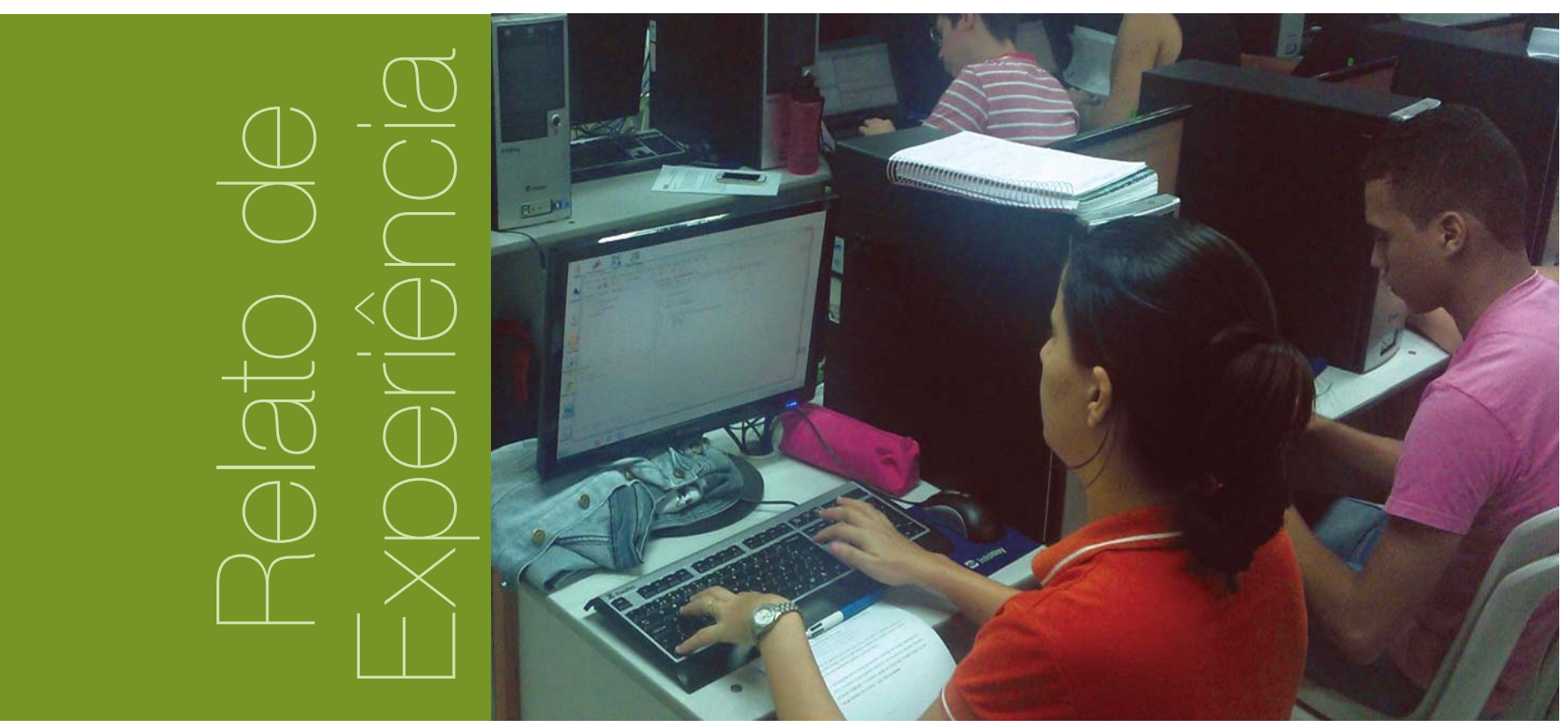

\title{
Capacitação em Java - contribuindo para a qualificação em Tecnologia da Informação no semiárido potiguar
}

Flávia Estélia Silva Coelho1 - flaviacoelho@ufersa.edu.br Paulo Gabriel Gadelha Queiroz² - pgabriel@ufersa.edu.br André Vitor de Sousa e Silva ${ }^{3}$ - andrevdj@gmail.com José Washington Vidal Morais Neto ${ }^{3}$ - moraisnetocc@gmail.com

\section{RESUMO}

A Capacitação em Java originou-se da necessidade de qualificação profissional, na região do semiárido potiguar, de estudantes dos níveis técnico e superior e de profissionais da tecnologia da informação quanto ao desenvolvimento de aplicações multiplataforma para a Internet; com o objetivo de auxiliar no aperfeiçoamento da sua competência técnica frente aos desafios impostos pelo mercado e a sociedade. Cerca de 40 pessoas foram instruídas, apoiadas por aulas práticas em laboratório.

\section{PALAVRAS-CHAVE}

Linguagem de programação Java. Qualificação profissional. Tecnologia da Informação.

\footnotetext{
1 Bacharel e Mestre em Ciência da Computação pela Universidade Federal de Campina Grande; professora do Bacharelado em Ciência da Computação da Universidade Federal Rural do Semi-Árido, atuando em Segurança da Informação e Metodologias de Ensino-Aprendizagem para a Computação. Em 2006, recebeu o título de Java Champion - Oracle Corporation.

2 Bacharel em Ciência da Computação pela Universidade Federal do Ceará, Mestre e Doutor em Computação pela Universidade de São Paulo; professor do Bacharelado em Ciência da Computação da Universidade Federal Rural do Semi-Árido, com experiência em Reúso, Sistemas Web, Geradores de Aplicações e Sistemas Embarcados Críticos.

3 Bacharelando em Ciência da Computação e bolsista do Projeto de Extensão Capacitação em Java - Edital UFERSA/PROEC 019/2013.
} 


\section{ABSTRACT}

The Capacitation in Java originated from the need for professional qualification, in the potiguar semiarid region, of technical and higher levels students and information technology professionals for the development of multiplatform applications to the Internet; in order to assist in the improvement of them technical competence due the challenges imposed by the market and society. About forty people were instructed, supported by practical lessons at lab.

\section{KEYWORDS}

Java programming language. Professional qualification. Information Technology.

\section{Introdução}

0 projeto de extensão Capacitação em Java foi fomentado pela Pró-Reitoria de Extensão e Cultura (PROEC) da Universidade Federal Rural do Semi-Árido (UFERSA) - Edital 019/2013 - e executado no período de abril de 2014 a março de 2015, com o objetivo de complementar a formação acadêmica de técnicos, universitários e profissionais da Tecnologia da Informação (TI), de MossoróRN e região, quanto ao desenvolvimento de aplicações multiplataforma para a Internet, auxiliando em sua inserção/manutenção no mercado de trabalho e disseminando a TI no semiárido potiguar.

Na região, é deficiente 0 aprofundamento em linguagens de programação de mercado, embora contempladas em cursos oferecidos pelo Instituto Federal de Educação, Ciência e Tecnologia do Rio Grande do Norte (IFRN), Universidade Estadual do Rio Grande do Norte (UERN) e UFERSA, de acordo com as grades curriculares vigentes ${ }^{4}$. Há, ainda, a escassez de empresas do ramo de treinamentos em TI direcionados ao desenvolvimento de software e pautados nas tendências para o mercado.

De acordo com a BRASSCOM (Associação Brasileira de Empresas de Tecnologia da Informação e Comunicação), havia um déficit de 45 mil profissionais formados na área (dados de 2013/2014) - evidenciando a programação e o desenvolvimento de aplicações.

Com a percepção de que essa conjuntura, aliada ao caráter inédito da proposta na região, oportunizaria ações de qualificç̧ão de estudantes e profissionais, foi concebida a capacitação em Java - linguagem de programação orientada a objetos para o desenvolvimento de aplicações multiplataforma.

Este relato de experiência expõe a metodologia empregada, os resultados obtidos e considerações finais, nas próximas seções.

\section{Metodologia}

Inicialmente, esclarece-se que Java foi escolhida com base em suas características próprias de qualidade e em sua aplicabilidade no mercado, enfatizada pelo "The TIOBE Programming Community Index" de janeiro de 2014 (TIOBE, 2014), cujos índices são considerados em tomadas de decisão.

As ferramentas de apoio ao desenvolvimento em Java são livres (Java SE JDK (Java Development Kit) 7 51 e NetBeans IDE 8.0.2), ilustradas na figura 1, reforçando a sua viabilidade em ações de capacitação, pois dispensa recursos financeiros para a aquisição de software de apoio.

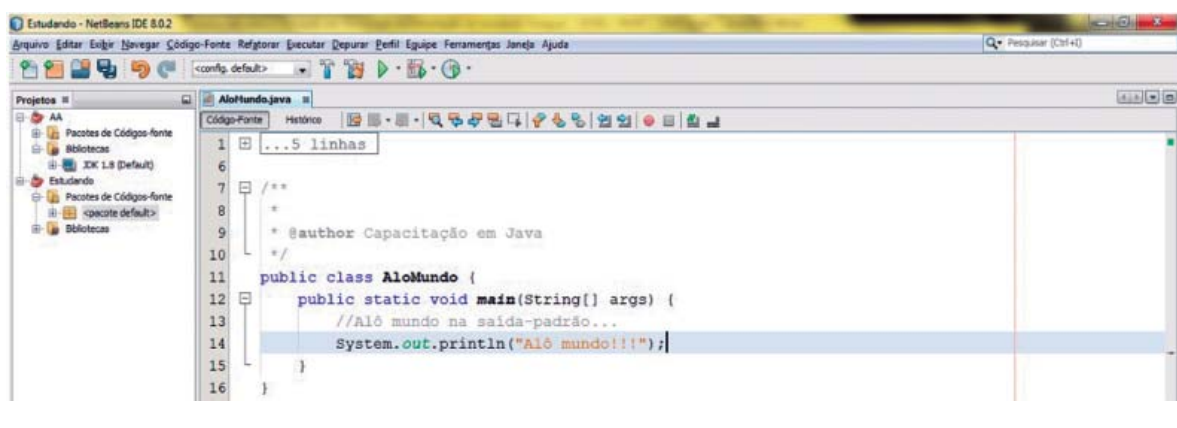

Figura 1: Área de trabalho do NetBeans 8.0.2 e utilização do JDK 7 u51.

Fonte: Autoria própria.

4 Dados obtidos a partir do Projeto Pedagógico dos cursos do IFRN, UERN e UFERSA 
0 projeto foi executado em laboratórios de computadores, conforme ilustra a figura 2, vinculados ao Bacharelado em Ciência da Computação, na UFERSA, em horários que não impediram as atividades de ensino e pesquisa realizados no âmbito do curso.

Figura 2: Realização

da Capacitação em

Java em Laboratório de

Computadores.

Fonte: Autoria própria.

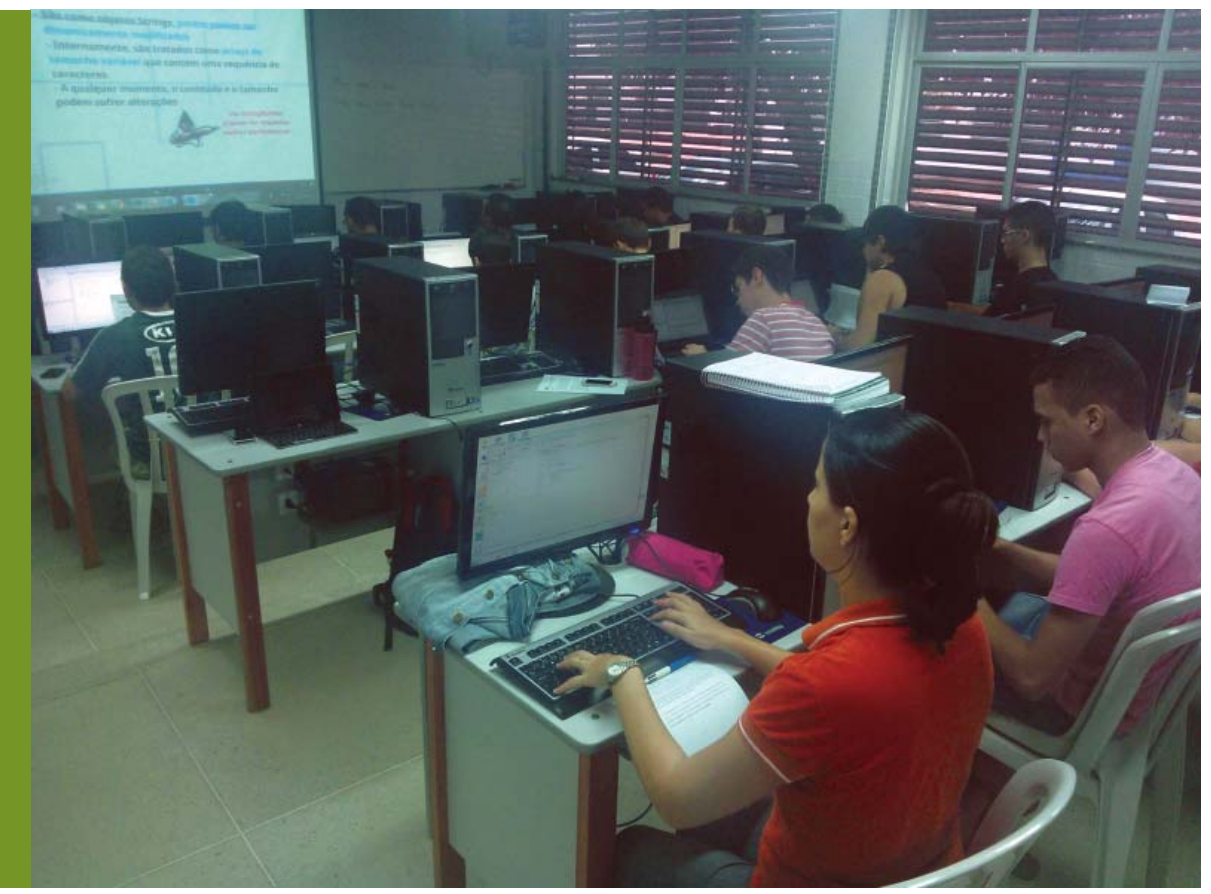

A capacitação foi efetuada à luz dos tópicos do exame de certificação Oracle Certified Associate, Java Standard Editon 7 Programmer (JAVASE, 2014), visando embasamento teórico-prático, por meio de exemplos, exercícios e questões de simulados do exame.

Assim, a Capacitação em Java encorajou o seu público-alvo, selecionado em função da ordem de inscrição, quanto à obtenção de certificação profissional - reconhecida no mercado como uma forma de garantia da habilidade e experiência em uma determinada tecnologia - agregando diferencial e credibilidade ao currículo.

0 projeto foi executado por meio de quatro módulos de 20h, executados em três turmas (de 30 participantes, cada) - matutino, vespertino e aos sábados, ministrados pelos docentes proponentes, auxiliados por dois bolsistas do Bacharelado em Ciência da Computação da UFERSA.

A metodologia de trabalho compreendeu a elaboração de material didático; a divulgação do calendário dos módulos junto à comunidade; a organização e a execução dos módulos; a elaboração e a aplicação dos exames de verificação de aprendizagem ao final de cada módulo; e a avaliação contínua da qualidade dos módulos.

Os quatro módulos englobaram os tópicos: Introdução à Tecnologia Java e à orientação a objetos, estruturas de decisão, criação e uso de arranjos, laços, métodos e encapsulamento, herança, polimorfismo, manipulação de erros, Java Data Base Connectivity (JDBC) e fundamentos de interfaces gráficas.

0 material didático foi elaborado de modo a estimular o desenvolvimento cognitivo dos participantes, baseado nas principais fontes bibliográficas sobre o tema (CORNELL, HORSTMANN, 2012; DEITEL, DEITEL 2010; TUTORIAL, 2014). Ressalta-se que o material instrucional elaborado foi disponibilizado aos participantes antecipadamente, sob o formato digital.

A execução dos módulos compreendeu os seguintes procedimentos didáticos: explanação dos tópicos supracitados, por meio de exemplos práticos, com 0 auxílio de ferramentas próprias para 0 desenvolvimento de código; exercícios práticos de desenvolvimento de código-fonte; resolução de questões de simulados do exame de certificação Oracle Certified Associate, Java SE 7 Programmer; disposição, no módulo final, de um projeto específico, a fim de que os participantes utilizassem Java em problemas reais. 


\section{Resultados}

Ao final de cada módulo, como um indicador do processo de ensino-aprendizagem, foi aplicado um exame de verificação de conhecimento (baseado em questões teórico-práticas), de modo que foi exigido $70 \%$ de aproveitamento no exame e 70\% de frequência para a obtenção do respectivo certificado. A tabela 1 exibe a quantidade de certificados emitidos por módulo.

\begin{tabular}{cc} 
Módulo & $\begin{array}{c}\text { Quantidade de } \\
\text { Certificados Emitidos }\end{array}$ \\
\hline 01 & 43 \\
\hline 02 & 37 \\
\hline 03 & 35 \\
\hline 04 & 23 \\
\hline
\end{tabular}

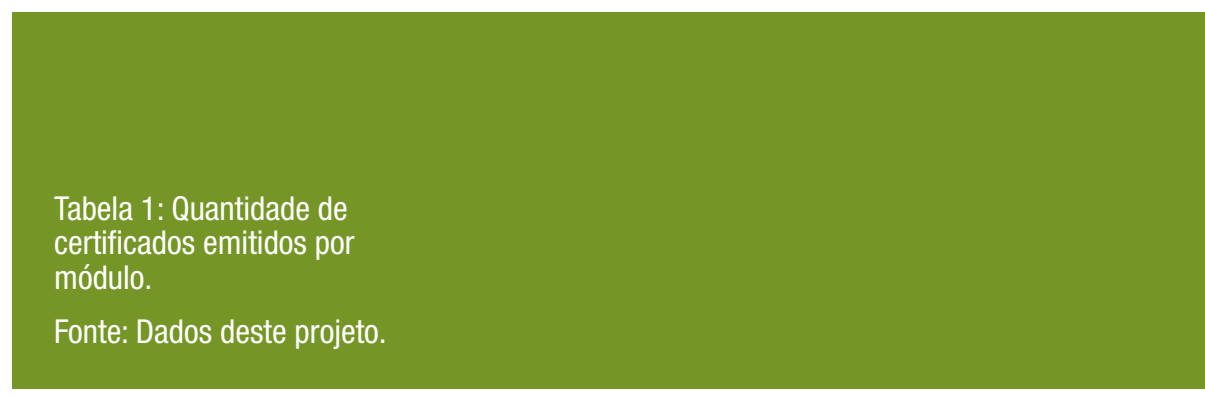

Ao final de cada módulo, os participantes preencheram um formulário de avaliação de qualidade considerando os critérios: cumprimento do horário das aulas, cumprimento do conteúdo programado, clareza na apresentação do conteúdo, e a coerência entre o nível de exigência no exame de verificação de aprendizagem e o conteúdo ministrado, entre outros. A figura 3 apresenta os resultados obtidos. Tais critérios foram adaptados a partir dos estabelecidos pela Comissão Própria de Avaliação (CPA) da UFERSA.

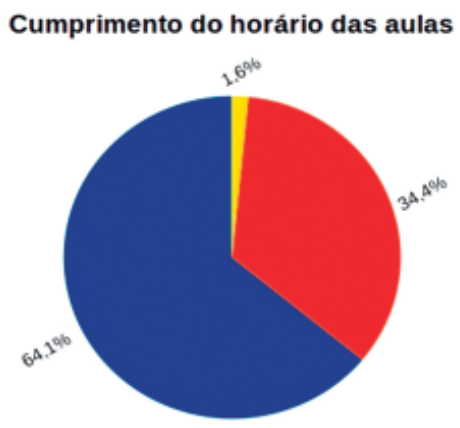

Disponibilidade do instrutor para tirar dúvidas durante as aulas

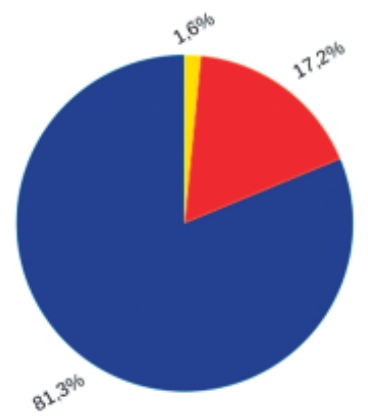

Incentivo à participaçāo dos alunos durante as aulas

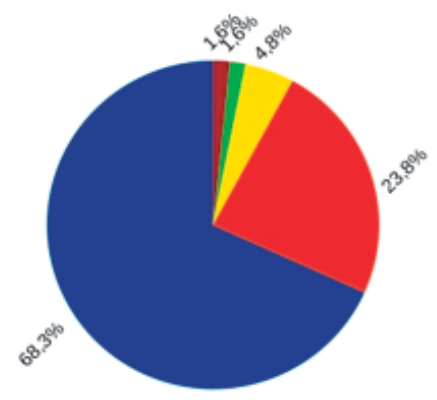

\section{Cumprimento do conteúdo programado}

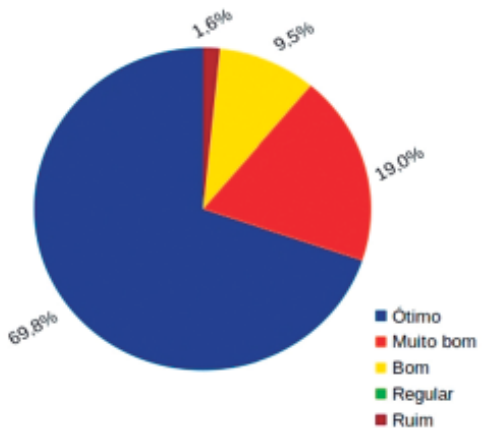

Clareza na apresentação do conteúdo

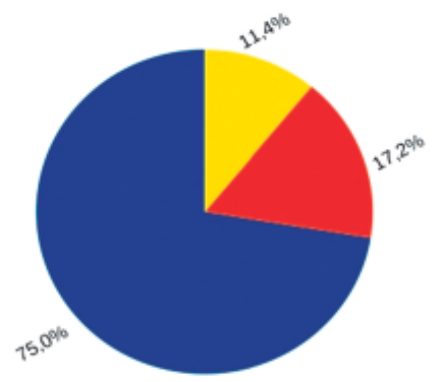

Coerência entre o nível de exigência no exame de verificação de aprendizagem (ou projeto) e o conteúdo ministrado

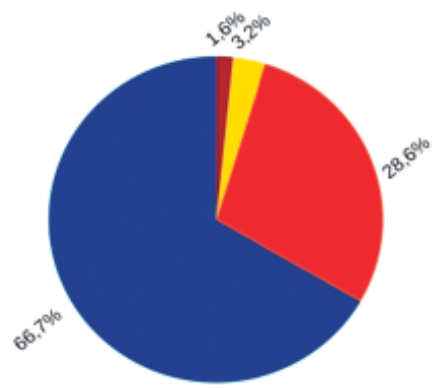

Figura 3: Resultados da avaliação de qualidade dos módulos ministrados.

Fonte: Dados deste projeto. 
No âmbito acadêmico, destaca-se a participação dos bolsistas no processo didático que baseia o ensino-aprendizagem, desde a concepção de material até a aplicação de exames de verificação de aprendizagem.

\section{Considerações finais}

Em seus pilares técnico-social, a ação auxiliou no desenvolvimento da competência técnica dos participantes frente aos desafios impostos quanto à sua qualificação profissional, conforme apresenta a figura 4.

\footnotetext{
"A capacitação foi muito proveitosa $e$ atendeu à proposta de conteúdo. Enfim, as aulas foram ótimas, pois a professora demonstrou segurança e clareza nas explicações dos assuntos abordados. Parabéns pelo trabalho de vocês!"

"Venho por meio deste mais uma vez parabenizar a equipe pelo excelente trabalho, fiz todos os módulos e acredito que adquiri um excelente conhecimento complementar na minha formação!"

"O minicurso foi um dos melhores que já fiz. Se Deus quiser estarei nos próximos. :) Parabéns pela iniciativa. $10 / "$

"O módulo foi aplicado de forma coerente, simples e ao mesmo tempo de forma objetiva. Parabéns a todos."

"A abordagem e o detalhamento do conteúdo foram excelentes, principalmente as questões de certificação trazidas para a aula, que nos fazem prestar atenção nos detalhes $e$ realmente aprender. Obrigado, parabéns!!! Mais um módulo finalizado com sucesso! Aguardarei o módulo IV, sugiro continuarmos nesse ritmo de aprendizado, que permite que todos os alunos fiquem nivelados!"
}

Figura 4: Depoimentos de participantes.

Ao término, estima-se que os participantes estão aptos para o desenvolvimento de aplicações simples orientadas a objetos, com a capacidade de aplicar o conhecimento adquirido em problemas reais e estimulados a buscar certificação profissional na área.

0 principal desafio observado foi o percentual de desistência: em média, 53\% por módulo. Para as próximas edições, planeja-se um acompanhamento aprimorado da assiduidade e das dificuldades individuais, além da atualização do conteúdo ministrado.

\section{Referências}

CORNELL, Gary; HORSTMANN, Cay. Core Java: Volume 1 - Fundamentals. Ninth Edition. Prentice Hall, 2012.

DEITEL, Paul. DEITEL, Harvey. Java: Como Programar. Oitava Edição. Pearson Education do Brasil, 2010.

JAVASE. Java Programmer Certification: Java SE 7 Certified Programmers. education. oracle.com, acesso em: abril de 2014.

TIOBE. Index for January 2014. Disponivel em: <www.tiobe.com/index.php/>. Acesso em: Janeiro de 2014.

TUTORIAL. The Java Tutorials. Disponivel em: <docs.oracle.com/javase/tutorial>. Acesso em: abril de 2014. 